\title{
Combining radiotherapy with sunitinib: lessons (to be) learned
}

\author{
Esther A. Kleibeuker ${ }^{1} \cdot$ Matthijs A. ten Hooven ${ }^{1} \cdot$ Henk M. Verheul $^{1}$. \\ Ben J. Slotman ${ }^{2} \cdot$ Victor L. Thijssen ${ }^{1,2}$
}

Received: 24 March 2015/Accepted: 14 July 2015/Published online: 23 July 2015

(C) The Author(s) 2015. This article is published with open access at Springerlink.com

\begin{abstract}
To improve the efficacy of radiotherapy (RTx), there is a growing interest in combining RTx with drugs that inhibit angiogenesis, i.e., the process of neo-vessel formation out of preexisting capillaries. A frequently used drug to inhibit angiogenesis is sunitinib (Sutent, SU11248), a receptor tyrosine kinase inhibitor that is currently FDA approved for the treatment of several cancer types. The current review presents an overview of the preclinical studies and clinical trials that combined sunitinib with RTx. We discuss the findings from preclinical and clinical observations with a focus on dose scheduling and commonly reported toxicities. In addition, the effects of combination therapy on tumor response and patient survival are described. Finally, the lessons learned from preclinical and clinical studies are summarized and opportunities and pitfalls for future clinical trials are presented.
\end{abstract}

Keywords Radiotherapy · Angiogenesis - Sunitinib · Combination therapy $\cdot$ Cancer

Esther A. Kleibeuker and Matthijs A. ten Hooven have contributed equally to this manuscript.

Electronic supplementary material The online version of this article (doi:10.1007/s10456-015-9476-3) contains supplementary material, which is available to authorized users.

Victor L. Thijssen

v.thijssen@vumc.nl

1 Department of Medical Oncology, VU University Medical Center, De Boelelaan 1118, 1081 HV Amsterdam, The Netherlands

2 Department of Radiation Oncology, VU University Medical Center, De Boelelaan 1118, 1081 HV Amsterdam, The Netherlands

\section{Introduction}

Radiotherapy (RTx) is effective against many tumor types and is used for curative and palliative purposes. Consequently, more than half of the cancer patients receive RTx $[1,2]$. Despite improvements in the efficacy of this treatment modality, there are still a considerable number of patients who show tumor recurrence $[1,3]$. To enhance the clinical benefit of RTx, the current research often aims to combine RTx with other treatment modalities, including angiogenesis inhibitors.

Angiogenesis is the process by which new blood vessels are formed out of preexisting vessels, and it is considered as one of the hallmarks of cancer [4]. In most tumors, an imbalance between pro- and anti-angiogenic factors exists due to tissue hypoxia. This imbalance induces the growth of an abnormally structured and leaky tumor vasculature [5]. Consequently, tissue oxygenation remains inadequate which not only causes continuous stimulation of angiogenesis but also interferes with RTx. Angiostatic drugs have been developed to counteract the imbalance between angioregulatory factors. Several of these drugs were shown to transiently induce vascular normalization in preclinical models [5]. Accordingly, the tumor perfusion briefly improved which was shown to increase the efficacy of RTx [6-8]. Whether this also occurs in human tumors is still under investigation.

In the last two decades, combinations of RTx with different angiostatic drugs have been evaluated [6, 9-11]. One of the frequently used drugs is sunitinib (Sutent, SU11248), a receptor tyrosine kinase inhibitor (TKI) that targets multiple receptors, including vascular endothelial growth factor receptor (VEGFR)-1, 2 and 3, platelet-derived growth factor receptor (PDGFR) $\alpha$ and $\beta$, stem cell growth factor (c-KIT), fms-like tyrosine kinase receptor 3 (FLT-3), 
neurotropic factor receptor (RET) and colony-stimulating factor (CSF-1R) $[12,13]$. Binding these receptors results in the inhibition of multiple signaling pathways that are key in the growth and survival of different tumor cells as well as of endothelial cell, i.e., the cells that align a blood vessel (Fig. 1) (for excellent reviews, see [12, 14]). As a result, sunitinib acts as an effective inhibitor of tumor growth, as demonstrated in variety of xenograft tumor models. In patients, sunitinib is approved for the treatment of pancreatic neuroendocrine tumors, metastatic renal cell carcinoma (mRCC) and imatinib-resistant gastrointestinal stromal tumors. To gain better insight into the applicability of this combination therapy, we evaluated the preclinical and clinical studies that combined sunitinib with RTx (for method of the literature searches, see supplementary data). We discuss the similarities and discrepancies between preclinical and clinical observations with a focus on dose scheduling and commonly reported toxicities. In addition, the effects on tumor response and patient survival are described. Finally, the opportunities and pitfalls for future clinical trials are presented.

\section{Preclinical assessment of combining RTx with sunitinib}

The effects of sunitinib monotherapy on angiogenesis and tumor growth are well studied and understood [12]. The effects of sunitinib in combination with RTx are less well studied, but it has been demonstrated that sunitinib given to endothelial cells (EC) before RTx enhances the apoptotic cell fraction $[15,16]$. On the other hand, El Kaffas et al. [17] did not observe an enhanced effect on apoptosis. In fact, they observed that EC apoptosis was reduced when sunitinib was combined with high-dose RTx (up to $16 \mathrm{~Gy}$ ). These discrepancies are most likely due to differences in dose scheduling emphasizing that dosing of radiation and sunitinib are important for their effects on EC apoptosis.

In tumor cells, it is generally observed that the combination therapy enhances apoptosis and reduces clonogenic survival. For example, in 4T1 breast cancer cells, the combination resulted in an increase in caspase-mediated apoptosis, while both treatments alone had no significant effect [18]. In two pancreatic adenocarcinoma cell lines (Mia$\mathrm{PaCa} 2$ and Panc-1), sunitinib combined with RTx decreased the activation of the Akt and Erk pathway and reduced the clonogenic survival [11]. Obviously, the responsiveness to the combination therapy depends on the presence of the receptors that are inhibited by sunitinib. This was illustrated in a study using prostate cancer cell lines lacking the target receptors in which the combination of sunitinib and RTx did not alter the clonogenic survival compared to RTx alone. The presence of at least one of the target receptors already resulted in decreased clonogenic survival during combination therapy [19]. Collectively, in vitro studies show that when combined with irradiation, sunitinib can enhance apoptosis and reduce cell survival in endothelial and tumor cells. These effects only occur when the treated cells express
Fig. 1 Schematic overview of the main receptor tyrosine kinases, the downstream signaling pathways, and biological processes that are targeted by sunitinib

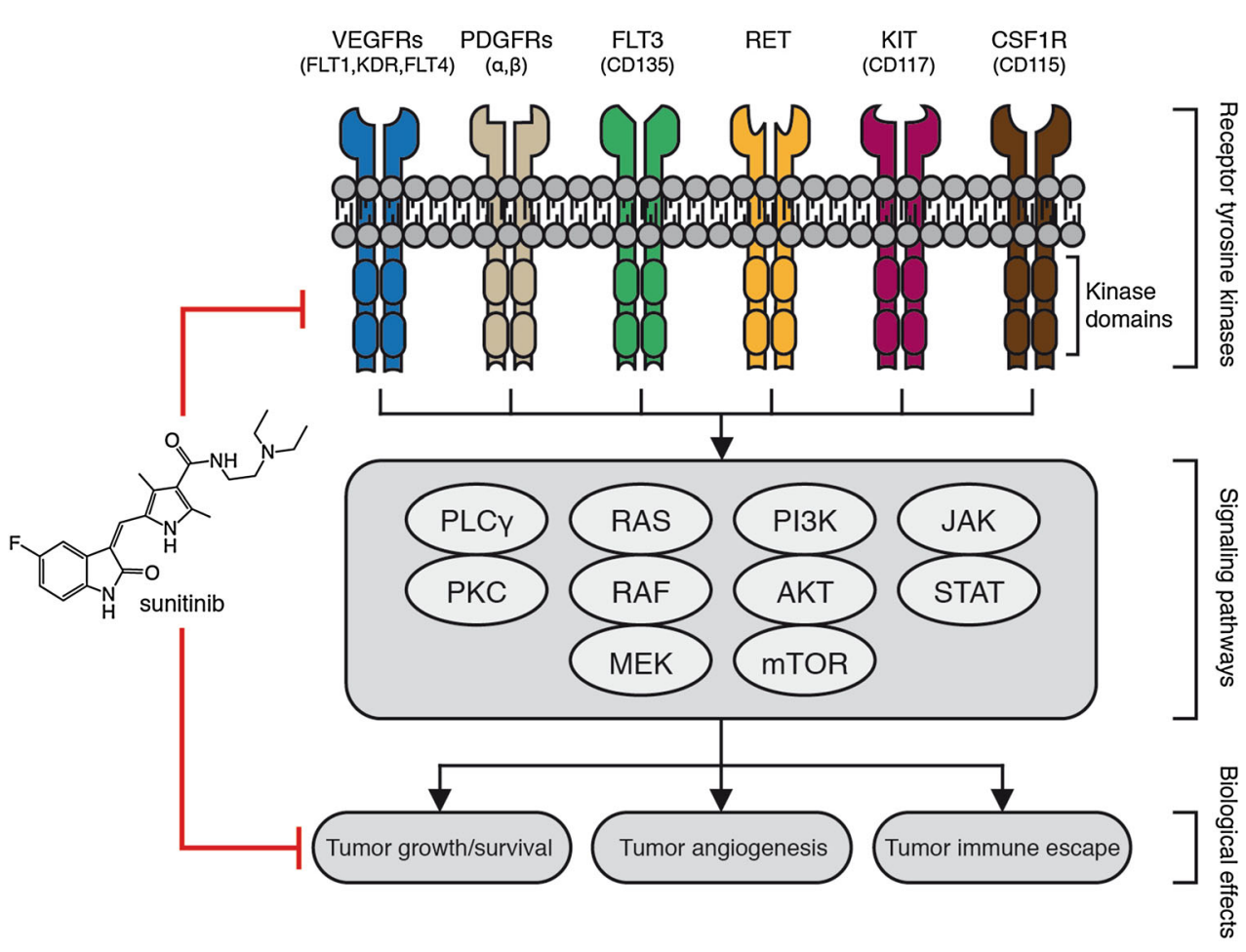


target receptors for sunitinib and during proper dose scheduling of both treatment modalities.

An important rationale to combine sunitinib with RTx was the observation that sunitinib can transiently improve tumor perfusion by normalizing the tumor vasculature. During this so-called normalization window, tissue oxygenation is increased which improves the efficacy of RTx. For example, dynamic contrast-enhanced (DCE) MRI analysis in a xenograft mouse model of kidney cancer revealed that improved tumor perfusion occurred after 3 days of sunitinib treatment. Applying RTx at day 3 while sunitinib treatment was continued for another 2 weeks appeared to further reduce tumor weights compared to either treatment alone although [20]. In a xenograft mouse model of squamous cell carcinoma, increased tumor oxygenation was observed after 4 days of sunitinib treatment. Applying RTx at day 4 resulted in a synergistically prolonged tumor growth delay as compared to sunitinib or RTx alone [21]. While these findings indicate that administration of sunitinib before RTx can improve therapeutic outcome due to vessel normalization, it has also been shown that simultaneous (concurrent) administration has beneficial effects on tumor growth inhibition. For example, in two studies using different xenograft models of human pancreatic adenocarcinoma, synergistic interactions on tumor growth delay were observed after concurrent treatment [11]. This could not be attributed to vascular normalization since a follow-up study using DCE-MRI showed that a decrease in $K$ (trans), i.e., reduced tissue perfusion, could predict the anti-tumor effect of the combination therapy [22]. Together with observations in other xenograft models [18, 23, 24], these findings show that also concurrent sunitinib can effectively reduce tumor growth. Most likely, this is related to the increased apoptosis of EC and tumor cells as observed in the in vitro studies.

Interestingly, in a xenograft prostate cancer model, the application of sunitinib after RTx is more beneficial regarding tumor growth delay compared to concurrent sunitinib [19]. This has also been described in xenograft models of Lewis lung carcinoma (LLC) [15] and colorectal carcinoma (HT29) [25]. The mechanisms behind the beneficial effect of sunitinib treatment during or after RTx are still not fully understood but appear to be distinct from vessel normalization. A possible explanation might again be the increased apoptosis as well as the induction of cell cycle arrest and senescence by sunitinib [26]. In addition, it is also known that RTx can increase the expression of vascular growth factors, such as VEGF, thereby inducing a vascular rebound effect and tumor regrowth [27-29]. Several of these growth factors activate signaling via receptors that are inhibited by sunitinib. Consequently, sunitinib given after RTx could counteract this rebound and thus prevent tumor regrowth.
Finally, an emerging concept that might contribute to the enhanced anti-tumor effect of the combination therapy involves the immune system. While describing the mechanisms and cells involved in this response is outside the scope of the current review, both sunitinib and RTx have been shown to affect many of the cellular players involved in modulation of the immune response in the tumor microenvironment [30-37]. Consequently, it is likely that the combination of both treatment modalities influences the anti-tumor immune response. However, further research is needed to elucidate their interaction, to determine the impact of different treatment schedules and to identify which immune cells are involved.

In summary, preclinical studies show the feasibility of combining sunitinib with RTx for cancer treatment. This involves different mechanisms, including vascular normalization, modulation of cell growth and apoptosis, as well as the alterations of the immune response. A major challenge will be to translate these preclinical findings into clinically relevant treatment protocols.

\section{Lessons learned from combining radiotherapy with sunitinib in the clinic}

Instigated by the promising results of preclinical research, several phase I and II clinical studies have been performed to assess the feasibility of combining sunitinib with RTx in cancer patients (Table 1). It should be noted that while the preclinical research aimed to elucidate the optimal scheduling, i.e., sunitinib either before, during, or after RTx, this has not been properly addressed in clinical trials. The latter studies focused more on feasibility and toxicity of the combination therapy, and in most studies, sunitinib was applied before and during RTx. Furthermore, in several studies, sunitinib maintenance therapy was an option for patients who well tolerated sunitinib treatment. Here, we focus on the two main schedules of sunitinib treatment in combination with RTx, i.e., a 6-week cycle (4 weeks on and 2 weeks off) and continuous administration.

\section{Radiotherapy in combination with 6-week cycle sunitinib treatment}

The standard administration of sunitinib is in 6-week treatment cycles with 4 weeks of $50 \mathrm{mg}$ /day sunitinib and 2 weeks no treatment $[12,38]$. This schedule is generally well tolerated and would allow patients to recover from the potential bone marrow toxicities [12]. The most commonly reported non-hematological adverse effects are gastrointestinal toxicities, fatigue, anorexia, hypertension, skin discoloration, and the hand-foot syndrome. Hematological toxicities include neutropenia, thrombocytopenia, anemia, 


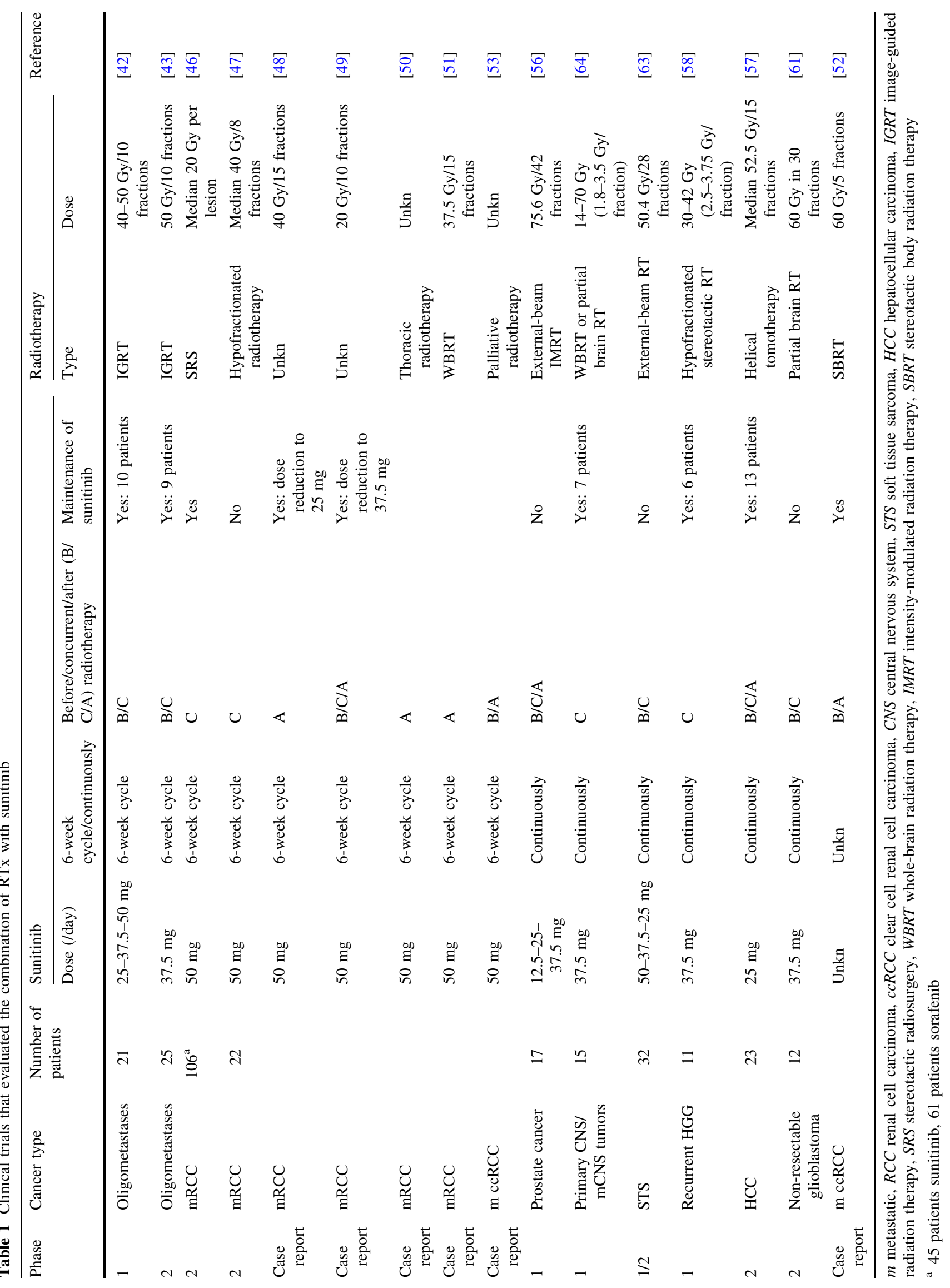


and leucopenia [38-41]. In general, these adverse effects are manageable and reversible.

\section{Toxicity}

The main concern when combining sunitinib with RTx in patients is the possible potentiation of the frequency and severity of side effects. To address this, Kao et al. performed a dose-escalation analysis of sunitinib both before and during RTx. At the maximum tolerated dose (MTD), i.e., $10 \times 5$ Gy IGRT and $37.5 \mathrm{mg}$ sunitinib/day, primarily grade 3 hematological toxicities were observed which were not reported as dose-limiting toxicities (DLT). Interestingly, the patients who did experience DLT had been pretreated with chemotherapy and received RTx for their liver metastases. They therefore excluded patients with liver metastasis $>6 \mathrm{~cm}$ for their follow-up phase II trials. Although it was stated that sunitinib did not enhanced RTx toxicities, they observed that RTx enhances the hematological grade 3/4 toxicities of sunitinib [42]. In the follow-up phase II trial, the most common grade 3 side effects were again hematological, while bleeding and liver function abnormalities occurred once. Although no grade 4 side effects were observed [43], the incidence of the side effects was higher compared to studies that evaluated RTx alone [44, 45]. Relatively mild toxicity profiles, including anemia and thrombocytopenia, were also reported in two phase II trials in patients with $\operatorname{mRCC}[46,47]$. Interestingly, the side effects were not potentiated by the combination. These differences are possibly related to the tumor type or to the different RTx doses and schedules that were applied. In addition, the duration of the sunitinib treatment, i.e., single cycle versus multiple cycles, might have been of influence. For example, in two case reports in which patients received additional cycles after RTx, the patients needed dose reduction due to intolerable side effects [48, 49].

Despite the encouraging toxicity profiles, some severe toxicities incidentally occur. Tong et al. [43] reported a grade 5 gastrointestinal hemorrhage and a fatal bronchobiliary fistula, possibly related to treatment. The latter was also described in a case report in a patient who received sunitinib after thoracic RTX for a subcarinal metastasis of renal cell carcinoma [50]. Staehler et al. reported that a patient who was still on treatment with sunitinib 3 months after stereotactic radiosurgery (SRS) experienced a fatal cerebral bleeding [47]. Concerns about combining RTx with sunitinib for brain metastasis in RCC have been raised in a case report in which a patient received sunitinib after whole-brain radiotherapy [51]. Altogether, these findings show that the combination therapy is generally well tolerated, but severe complications can occur incidentally.

\section{Clinical benefit}

While the clinical benefit of the combination therapy has not been properly evaluated, the results from the phase I/II trials are encouraging. In patients with oligometastases, Kao et al. [42] reported complete response (CR) or partial response $(\mathrm{PR})$ in $59 \%$ of patients. Stable disease (SD) was reached in $28 \%$ of the patients, while progressive disease (PD) occurred in the remaining patients. These response rates were favorable compared to systemic therapy alone [42]. This trial was followed by a phase II trial in a comparable patient group with 2-year follow-up [43]. The 18-month local control was $75 \%$, and distant control of $52 \%$. The median time until progression was 9.5 months, and at the end of the study, 18 patients were alive, 11 of whom without disease [43]. Encouraging results were also observed in patients with $\mathrm{mRCC}$ who received either sunitinib combined with single-fraction SRS [46] or high-dose hypofractionated RTx [47]. It was stated that these results were not explained by the single therapies alone which is supported by several case reports that described the beneficial effects of this combination therapy in patients with $\operatorname{mRCC}[48,49,52,53]$. Together, these findings demonstrate that the combination of sunitinib and RTx might induce clinical responses in different tumor types. However, a phase III clinical trial is required in order to draw firm conclusions.

Overall, the toxicities of the concurrent combination of RTx and sunitinib administered in 6-week cycles appears to depend on the duration and dose of sunitinib treatment, on the concurrent dose of RTx, but also on previous chemoradiation and type of metastases, e.g., liver or brain. Nevertheless, the combination therapy is generally well tolerated and appears to result in encouraging anti-tumor and clinical responses in a diverse range of tumors. All this warrants additional studies to further establish the clinical benefit of the combination therapy and to address the importance of dose scheduling on treatment efficacy and toxicity.

\section{Radiotherapy in combination with continuous sunitinib treatment}

The disadvantage of interrupting the sunitinib treatment is that it potentially allows proliferation of tumor cells between the cycles. For this reason, continuous dosing of monotherapy sunitinib has also been tested. For this, the daily dose of sunitinib was reduced to $37.5 \mathrm{mg} /$ day. This regimen is also well tolerated, with a similar toxicity profile compared to the 4 weeks on and 2 weeks off schedule [12, 54, 55].

\section{Toxicity}

Similar to the studies using a 6-week cycle treatment, the trials combining continuous sunitinib with RTx have 
carefully evaluated the toxicity profile. In patients with localized high-risk prostate cancer, the safe dose of continuous sunitinib in combination with external-beam RTx was determined at $25 \mathrm{mg} /$ day, at which one out of six patients developed a DLT (grade 3 fatigue). The most common side effects were fatigue, neutropenia, anemia, and hypertension [56]. In a phase II study including patients with locally advanced hepatocellular carcinoma (HCC), similar common and manageable side effects were reported when continuous sunitinib treatment $(25 \mathrm{mg} /$ day $)$ was combined with $\mathrm{RTx}$ [57]. This relatively mild toxicity profile is interesting, since all patients received RTx on the liver and, as stated before, liver irradiation appeared to be an important factor decreasing the tolerability of the sunitinib dose [42]. Possibly, the lower dose of sunitinib and the different schedules underlie the differences in the side effects. However, other factors such as tumor type and dosing of RTx could also have contributed, warranting further research.

In a phase I study in patients with primary and metastatic central nervous system malignancies, the combination of concurrent sunitinib (37.5 mg/day) and cranial RTx mainly induced manageable toxicity. The incidence and severity of the toxicities were independent of type and dose of the RTx [58]. Since the toxicity rate of the combination treatment was slightly higher compared to studies in which patients only received cranial RTx, addition of sunitinib appeared to enhance the side effects [59, 60]. In a pilot study with recurrent high-grade glioma patients, $90 \%$ experienced grade $1 / 2$ toxicity (mainly hematological), while only one patient had a DLT (grade 4, oral ulcer) [58]. In a following phase II study with 12 newly diagnosed, non-resectable glioblastoma patients, again the most frequently reported side effects were grade $1 / 2$, although some grade 3 toxicities were reported [61]. However, since only two patients received the combined therapy, this should be evaluated as sunitinib monotherapy. With this in mind, sunitinib treatment was stated to be well tolerated but did not result in anti-tumor responses [61]. Comparable results were found in glioma patients who received continuous sunitinib as monotherapy prior to RTx and/or chemotherapy [62].

In contrast to the mild toxicities described so far, a phase I/II study in patients with soft tissue sarcoma was closed prematurely due to DLT when sunitinib was combined with RTx [63]. Seven patients had received $50 \mathrm{mg}$ daily for 2 weeks before RTx, followed by $25 \mathrm{mg}$ daily during RTx. Dose-limiting toxicities were observed in four patients (grade 3/4). Subsequently, the starting dose of sunitinib was reduced to $37.5 \mathrm{mg}$ daily, followed by $37.5 \mathrm{mg}$ daily during RTx. The next two patients showed DLTs (grade 3), which led to premature closure of the study. Because of the lack of clinical benefit and the majority of patients showing DLTs, the schedule and dosing of sunitinib and RTx was not recommended in this patient group [63].
Altogether, continuous dosing of sunitinib combined with RTx is generally well tolerated, although due to toxicities, a lower daily dose for sunitinib is usually required as compared to the 6-week cycle. Furthermore, for specific tumor types, this combination is not recommended as it will induce DLT and does not improve patient outcome.

\section{Clinical benefit}

Similar to the 6-week cycle treatment, the phase I/II trials that combine continuous sunitinib with RTx show encouraging results. A study in prostate cancer patients with a median follow-up of 19.6 months showed a median posttreatment PSA of $<0.1 \mathrm{ng} / \mathrm{ml}$. Only two out of 17 patients showed treatment failure [56]. The suggestion of clinical benefit was also reported in patients with recurrent highgrade glioma [58] as well as in patients with primary and metastatic central nervous system malignancies [64]. In the latter study, the 6-month PFS was higher compared to studies that applied cranial RTx alone for patients with brain metastasis $[65,66]$. Promising clinical responses were also observed in a study with locally advanced HCC patients [57]. Interestingly, several patients continued sunitinib treatment until disease progression. The median time to progression in these patients was 10 months compared to 4 months in those who did not receive maintenance sunitinib [57]. This observation corresponds with results described in preclinical studies, where maintenance therapy was the main factor contributing to tumor growth reduction [19, 26, 67].

While several studies indicated a potential benefit of the combination therapy, less promising responses were reported in a phase II study with glioblastoma patients in which sunitinib was started 8 weeks before RTx [61]. Only $41.7 \%$ of patients completed the 8 weeks of sunitinib prior to RTx due to tumor progression and neurological deterioration. Furthermore, none of the patients was alive after 1 year [61]. A lack of additional clinical benefit was also observed in a phase I/II study with soft tissue sarcoma patients [63].

Together, these studies demonstrate that-similar to 6-week cycle treatment-continuous sunitinib treatment combined with RTx can induce clinical responses. Also in line with 6-week cycle treatment, the response appears to depend on the tumor type and dose scheduling. Interestingly, it is suggested that mainly the maintenance sunitinib treatment contributes to better and longer disease responses.

\section{Future prospects: lessons to be learned}

The results of the preclinical research and clinical trials have provided valuable insights into the feasibility to combine sunitinib with RTx. Furthermore, several clinical 
trials are ongoing (Table 2) that will further address the clinical applicability of this combination therapy. Especially with regard to dose scheduling and toxicity lessons have to be learned. Although the combination therapy appears to be well tolerated, the MTD of sunitinib depends on the scheduling that is used. Compared to the common dose for sunitinib monotherapy, i.e., $50 \mathrm{mg} /$ day, the combination with RTx requires dose reductions to $37.5 \mathrm{mg} /$ day in case of a 6-week cycle treatment and $25 \mathrm{mg} /$ day for continuous administration [42, 43, 56, 57]. While such dose reductions generally resulted in lower toxicity rates [42, 47], there are still concerns regarding rare but severe side effects, such as perforations in the gastrointestinal tract or severe hemorrhages. Interestingly, it has been described in case reports that dose reductions do not affect tumor responses [48, 49], possibly because sunitinib is known to accumulate in the tumor [25]. This is also supported by our recent preclinical study in which sunitinib dose reductions of $50 \%$ did not affect the tumor growth delay in combination with RTx [67]. Dose reduction of sunitinib would not only reduce the severity and frequency of side effects, but also lower the financial burden on the healthcare system [68]. Therefore, future research should further resolve whether low-dose sunitinib treatment, i.e., dosing below the MTD, would affect the response rates in patients. Measurements of tumor perfusion during treatment could be of value to get better insight into the dose-response relationship. Regarding this, an ongoing phase I study (Table 2, NCT01308034) performs DCE-ultrasonography (DCE-US) after start of sunitinib to measure neo-angiogenesis. These data can provide valuable insights into the dose-dependent intra-tumoral effects of sunitinib on perfusion and angiogenesis.

Another important lesson to be learned concerns the proper scheduling of both treatment modalities. Sunitinib treatment is often applied several weeks before RTx. This might be beneficial since sunitinib treatment has been shown to induce transient vascular normalization in preclinical models, resulting in improved tumor oxygenation [20, 21, 69]. However, evidence for such a response in patients should be addressed by future trials, for example with perfusion measurements using DCE-MRI [70-72] or by hypoxia imaging techniques such as FMISO PET [73, 74]. On the other hand, in the preclinical models, vascular normalization occurs rapidly after the start of treatment and lasts for only a few days. This suggests that even when vascular normalization occurs in the clinical setting, the window of opportunity has already passed when sunitinib treatment is given for several weeks prior to RTx. This is supported by a study of Lewin et al. [63] where DCE-MRI and FAZA-PET/CT analyses showed decreased tumor perfusion and increased tumor hypoxia after 2 weeks of sunitinib.
While the clinical benefit of sunitinib treatment prior to RTx is still unclear, there is ample preclinical evidence supporting a beneficial role of sunitinib maintenance therapy after RTx $[15,19,57]$. The mechanisms responsible for this are poorly understood but appear to be distinct from vessel normalization. Possibly, sunitinib counteracts the vascular rebound effect induced by RTx or improves the anti-tumor immune response. Unraveling these mechanisms requires further research. Furthermore, most clinical trials in which patients received maintenance sunitinib did not report on differences in tumor response rates or survival compared to patients who did not continue sunitinib treatment [42, 43, 46, 64]. This provides an opportunity for future research, and several ongoing studies have included sunitinib treatment after RTx (Table 2). These studies might give more insight into the potentially favorable effect of sunitinib maintenance therapy.

Another unexplored area in scheduling is the interaction between both treatment modalities when sunitinib has been part of a previous treatment regime. It has not been established whether RTx can be applied safely after longterm sunitinib treatment, whether sunitinib treatment has to be discontinued, or whether continuation improves tumor outcome. It has been shown in $\mathrm{mRCC}$ patients that discontinuation of sunitinib rapidly results in an angiogenic rebound [75]. Whether this happens in other tumor types as well and how this affects the efficacy and toxicity of subsequent RTx should be further addressed.

Of note, while the current review is focused on combining sunitinib with RTx, many of the future challenges reported here for sunitinib, also apply to other angiogenesis inhibitors. Differences in dose scheduling, type of drug, and tumor type will influence the therapeutic efficacy [76]. For example, the combination of bevacizumab (anti-VEGF antibody) and RTx can induce encouraging response rates [77, 78] or increased toxicity without any response [79, 80]. Similar divergent responses have been described for the combination of RTx with sorafenib, a TKI that targets several angiogenesis-related proteins, including VEGFR, PDGFR, and Raf kinases [81-83]. Unraveling the similarities and differences when combining angiostatic drugs with RTx requires a more systematic preclinical and clinical approach including, for example, imaging techniques to measure perfusion and early tumor responses [84].

In conclusion, the combination of sunitinib and RTx is a promising treatment strategy which deserves further preclinical and clinical investigation. Given the observed increased side effects of this combination therapy, research should focus on determining the maximum effective dose of sunitinib as well as on deciphering the optimal treatment schedules of the combination therapy. With all the lessons learned and lessons to be learned, the translation of the insights from phase I/II clinical trials into clinical phase III 


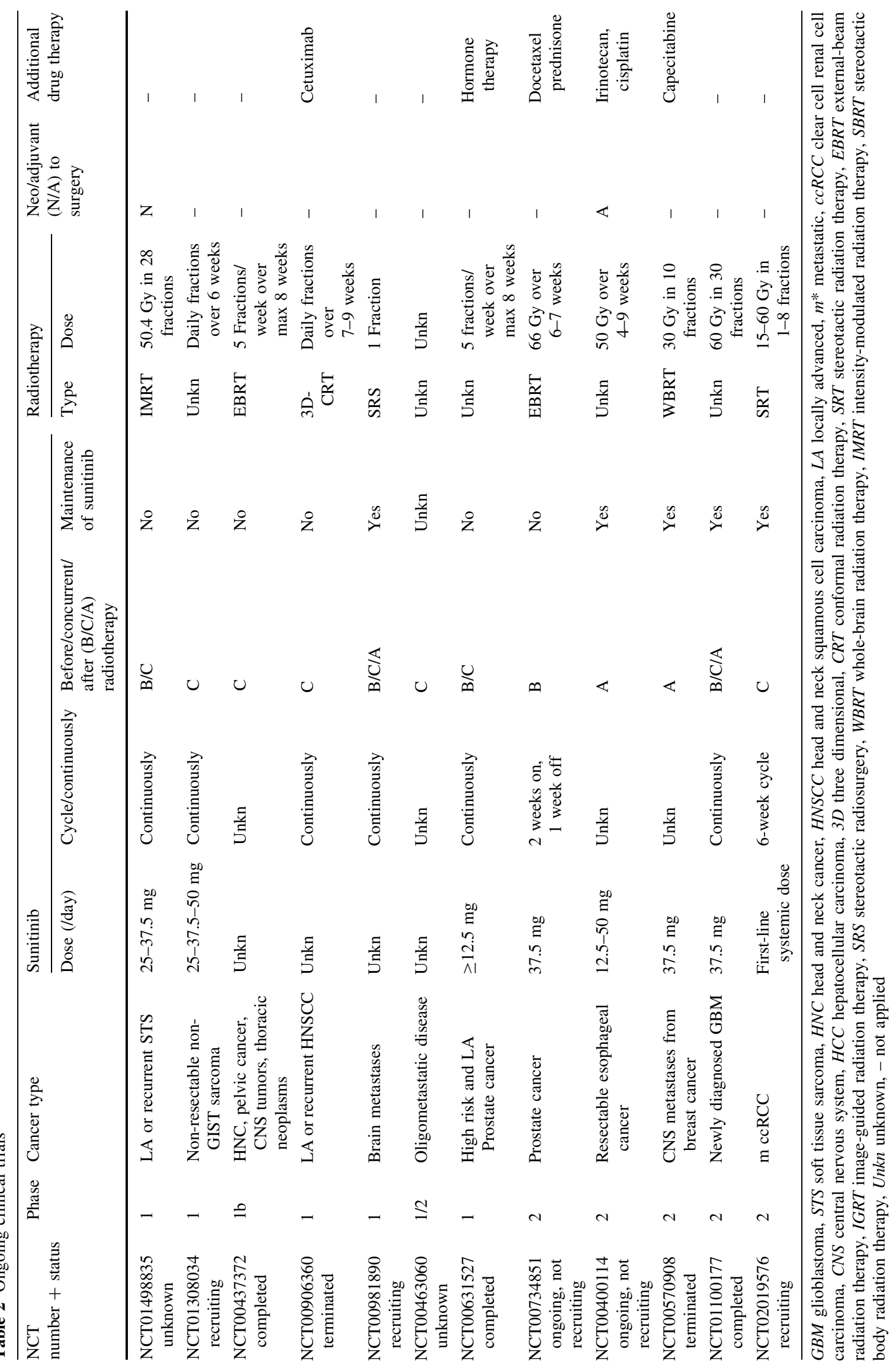


trials will reveal whether this combination therapy is really beneficial and could be implemented in daily clinical practice.

Open Access This article is distributed under the terms of the Creative Commons Attribution 4.0 International License (http://crea tivecommons.org/licenses/by/4.0/), which permits unrestricted use, distribution, and reproduction in any medium, provided you give appropriate credit to the original author(s) and the source, provide a link to the Creative Commons license, and indicate if changes were made.

\section{References}

1. Bernier J, Hall EJ, Giaccia A (2004) Radiation oncology: a century of achievements. Nat Rev Cancer 4:737-747

2. Delaney G, Jacob S, Featherstone C, Barton M (2005) The role of radiotherapy in cancer treatment: estimating optimal utilization from a review of evidence-based clinical guidelines. Cancer 104:1129-1137

3. Begg AC, Stewart FA, Vens C (2011) Strategies to improve radiotherapy with targeted drugs. Nat Rev Cancer 11:239-253

4. Hanahan D, Weinberg RA (2011) Hallmarks of cancer: the next generation. Cell 144:646-674

5. Jain RK (2005) Normalization of tumor vasculature: an emerging concept in antiangiogenic therapy. Science 307:58-62

6. Dings RP, Loren M, Heun H, McNiel E, Griffioen AW, Mayo $\mathrm{KH}$, Griffin RJ (2007) Scheduling of radiation with angiogenesis inhibitors anginex and avastin improves therapeutic outcome via vessel normalization. Clin Cancer Res 13:3395-3402

7. Winkler F, Kozin SV, Tong RT, Chae SS, Booth MF, Garkavtsev $\mathrm{I}, \mathrm{Xu} \mathrm{L}$ et al (2004) Kinetics of vascular normalization by VEGFR2 blockade governs brain tumor response to radiation: role of oxygenation, angiopoietin-1, and matrix metalloproteinases. Cancer Cell 6:553-563

8. McGee MC, Hamner JB, Williams RF, Rosati SF, Sims TL, Ng CY, Gaber MW et al (2010) Improved intratumoral oxygenation through vascular normalization increases glioma sensitivity to ionizing radiation. Int J Radiat Oncol Biol Phys 76:1537-1545

9. Gorski DH, Mauceri HJ, Salloum RM, Gately S, Hellman S, Beckett MA, Sukhatme VP et al (1998) Potentiation of the antitumor effect of ionizing radiation by brief concomitant exposures to angiostatin. Cancer Res 58:5686-5689

10. Zips D, Krause M, Hessel F, Westphal J, Bruchner K, Eicheler W, Dorfler A et al (2003) Experimental study on different combination schedules of VEGF-receptor inhibitor PTK787/ ZK222584 and fractionated irradiation. Anticancer Res 23:3869-3876

11. Cuneo KC, Geng L, Fu A, Orton D, Hallahan DE, Chakravarthy AB (2008) SU11248 (sunitinib) sensitizes pancreatic cancer to the cytotoxic effects of ionizing radiation. Int J Radiat Oncol Biol Phys 71:873-879

12. Faivre S, Demetri G, Sargent W, Raymond E (2007) Molecular basis for sunitinib efficacy and future clinical development. Nat Rev Drug Discov 6:734-745

13. Mendel DB, Laird AD, Xin X, Louie SG, Christensen JG, Li G, Schreck RE et al (2003) In vivo antitumor activity of SU11248, a novel tyrosine kinase inhibitor targeting vascular endothelial growth factor and platelet-derived growth factor receptors: determination of a pharmacokinetic/pharmacodynamic relationship. Clin Cancer Res 9:327-337
14. Aparicio-Gallego G, Blanco M, Figueroa A, Garcia-Campelo R, Valladares-Ayerbes M, Grande-Pulido E, Anton-Aparicio L (2011) New insights into molecular mechanisms of sunitinib-associated side effects. Mol Cancer Ther 10:2215-2223

15. Schueneman AJ, Himmelfarb E, Geng L, Tan J, Donnelly E, Mendel D, McMahon G et al (2003) SU11248 maintenance therapy prevents tumor regrowth after fractionated irradiation of murine tumor models. Cancer Res 63:4009-4016

16. Zhang HP, Takayama K, Su B, Jiao XD, Li R, Wang JJ (2011) Effect of sunitinib combined with ionizing radiation on endothelial cells. J Radiat Res 52:1-8

17. El Kaffas A, Al-Mahrouki A, Tran WT, Giles A, Czarnota GJ (2013) Sunitinib effects on the radiation response of endothelial and breast tumor cells. Microvasc Res

18. Zwolak P, Jasinski P, Terai K, Gallus NJ, Ericson ME, Clohisy DR, Dudek AZ (2008) Addition of receptor tyrosine kinase inhibitor to radiation increases tumour control in an orthotopic murine model of breast cancer metastasis in bone. Eur J Cancer 44:2506-2517

19. Brooks C, Sheu T, Bridges K, Mason K, Kuban D, Mathew P, Meyn R (2012) Preclinical evaluation of sunitinib, a multi-tyrosine kinase inhibitor, as a radiosensitizer for human prostate cancer. Radiat Oncol 7:154

20. Hillman GG, Singh-Gupta V, Al-Bashir AK, Yunker CK, Joiner MC, Sarkar FH, Abrams J et al (2011) Monitoring sunitinibinduced vascular effects to optimize radiotherapy combined with soy isoflavones in murine xenograft tumor. Transl Oncol $4: 110-121$

21. Matsumoto S, Batra S, Saito K, Yasui H, Choudhuri R, Gadisetti C, Subramanian S et al (2011) Anti-angiogenic agent sunitinib transiently increases tumor oxygenation and suppresses cycling hypoxia. Cancer Res

22. Casneuf VF, Delrue L, van Damme N, Demetter P, Robert P, Corot C, Duyck P et al (2011) Noninvasive monitoring of therapy-induced microvascular changes in a pancreatic cancer model using dynamic contrast-enhanced magnetic resonance imaging with P846, a new low-diffusible gadolinium-based contrast agent. Radiat Res 175:10-20

23. Bozec A, Sudaka A, Toussan N, Fischel JL, Etienne-Grimaldi MC, Milano G (2009) Combination of sunitinib, cetuximab and irradiation in an orthotopic head and neck cancer model. Ann Oncol 20:1703-1707

24. Yoon SS, Stangenberg L, Lee YJ, Rothrock C, Dreyfuss JM, Baek KH, Waterman PR et al (2009) Efficacy of sunitinib and radiotherapy in genetically engineered mouse model of soft-tissue sarcoma. Int J Radiat Oncol Biol Phys 74:1207-1216

25. Gotink KJ, Broxterman HJ, Labots M, de Haas RR, Dekker H, Honeywell RJ, Rudek MA et al (2011) Lysosomal sequestration of sunitinib: a novel mechanism of drug resistance. Clin Cancer Res 17:7337-7346

26. Zhu Y, Xu L, Zhang J, Hu X, Liu Y, Yin H, Lv T et al (2013) Sunitinib induces cellular senescence via p53/Dec1 activation in renal cell carcinoma cells. Cancer Sci 104:1052-1061

27. Dalrymple SL, Becker RE, Zhou H, DeWeese TL, Isaacs JT (2012) Tasquinimod prevents the angiogenic rebound induced by fractionated radiation resulting in an enhanced therapeutic response of prostate cancer xenografts. Prostate 72:638-648

28. Hou H, Lariviere JP, Demidenko E, Gladstone D, Swartz H, Khan N (2009) Repeated tumor pO(2) measurements by multi-site EPR oximetry as a prognostic marker for enhanced therapeutic efficacy of fractionated radiotherapy. Radiother Oncol 91:126-131

29. Park JS, Qiao L, Su ZZ, Hinman D, Willoughby K, McKinstry R, Yacoub A et al (2001) Ionizing radiation modulates vascular endothelial growth factor (VEGF) expression through multiple mitogen activated protein kinase dependent pathways. Oncogene 20:3266-3280 
30. Bose A, Taylor JL, Alber S, Watkins SC, Garcia JA, Rini BI, Ko JS et al (2011) Sunitinib facilitates the activation and recruitment of therapeutic anti-tumor immunity in concert with specific vaccination. Int J Cancer 129:2158-2170

31. Dirkx AE, Oude Egbrink MG, Castermans K, van der Schaft DW, Thijssen VL, Dings RP, Kwee L et al (2006) Anti-angiogenesis therapy can overcome endothelial cell anergy and promote leukocyte-endothelium interactions and infiltration in tumors. FASEB J 20:621-630

32. Shrimali RK, Yu Z, Theoret MR, Chinnasamy D, Restifo NP, Rosenberg SA (2010) Antiangiogenic agents can increase lymphocyte infiltration into tumor and enhance the effectiveness of adoptive immunotherapy of cancer. Cancer Res 70:6171-6180

33. Huang H, Langenkamp E, Georganaki M, Loskog A, Fuchs PF, Dieterich LC, Kreuger J et al (2015) VEGF suppresses T-lymphocyte infiltration in the tumor microenvironment through inhibition of NF-kappaB-induced endothelial activation. FASEB J 29:227-238

34. Shahabi V, Postow MA, Tuck D, Wolchok JD (2015) Immunepriming of the tumor microenvironment by radiotherapy: rationale for combination with immunotherapy to improve anticancer efficacy. Am J Clin Oncol 38:90-97

35. Sharma A, Bode B, Wenger RH, Lehmann K, Sartori AA, Moch $\mathrm{H}$, Knuth A et al (2011) $\gamma$-Radiation promotes immunological recognition of cancer cells through increased expression of cancer-testis antigens in vitro and in vivo. PLoS ONE 6:e28217

36. Burnette BC, Liang H, Lee Y, Chlewicki L, Khodarev NN, Weichselbaum RR, Fu YX et al (2011) The efficacy of radiotherapy relies upon induction of type I interferon-dependent innate and adaptive immunity. Cancer Res 71:2488-2496

37. Dewan MZ, Galloway AE, Kawashima N, Dewyngaert JK, Babb JS, Formenti SC, Demaria S (2009) Fractionated but not singledose radiotherapy induces an immune-mediated abscopal effect when combined with anti-CTLA- 4 antibody. Clin Cancer Res 15:5379-5388

38. Faivre S, Delbaldo C, Vera K, Robert C, Lozahic S, Lassau N, Bello C et al (2006) Safety, pharmacokinetic, and antitumor activity of SU11248, a novel oral multitarget tyrosine kinase inhibitor, in patients with cancer. J Clin Oncol 24:25-35

39. Motzer RJ, Hutson TE, Tomczak P, Michaelson MD, Bukowski RM, Rixe O, Oudard S et al (2007) Sunitinib versus interferon alfa in metastatic renal-cell carcinoma. N Engl J Med 356:115-124

40. Motzer RJ, Michaelson MD, Redman BG, Hudes GR, Wilding G, Figlin RA, Ginsberg MS et al (2006) Activity of SU11248, a multitargeted inhibitor of vascular endothelial growth factor receptor and platelet-derived growth factor receptor, in patients with metastatic renal cell carcinoma. J Clin Oncol 24:16-24

41. Demetri GD, van Oosterom AT, Garrett CR, Blackstein ME, Shah MH, Verweij J, McArthur G et al (2006) Efficacy and safety of sunitinib in patients with advanced gastrointestinal stromal tumour after failure of imatinib: a randomised controlled trial. Lancet 368:1329-1338

42. Kao J, Packer S, Vu HL, Schwartz ME, Sung MW, Stock RG, Lo YC et al (2009) Phase 1 study of concurrent sunitinib and imageguided radiotherapy followed by maintenance sunitinib for patients with oligometastases: acute toxicity and preliminary response. Cancer 115:3571-3580

43. Tong CC, Ko EC, Sung MW, Cesaretti JA, Stock RG, Packer SH, Forsythe K et al (2012) Phase II trial of concurrent sunitinib and image-guided radiotherapy for oligometastases. PLoS ONE 7:e36979

44. Milano MT, Katz AW, Muhs AG, Philip A, Buchholz DJ, Schell MC, Okunieff P (2008) A prospective pilot study of curativeintent stereotactic body radiation therapy in patients with 5 or fewer oligometastatic lesions. Cancer 112:650-658
45. Salama JK, Chmura SJ, Mehta N, Yenice KM, Stadler WM, Vokes EE, Haraf DJ et al (2008) An initial report of a radiation dose-escalation trial in patients with one to five sites of metastatic disease. Clin Cancer Res 14:5255-5259

46. Staehler M, Haseke N, Nuhn P, Tullmann C, Karl A, Siebels M, Stief CG et al (2011) Simultaneous anti-angiogenic therapy and single-fraction radiosurgery in clinically relevant metastases from renal cell carcinoma. BJU Int 108:673-678

47. Staehler M, Haseke N, Stadler T, Nuhn P, Roosen A, Stief CG, Wilkowski R (2012) Feasibility and effects of high-dose hypofractionated radiation therapy and simultaneous multi-kinase inhibition with sunitinib in progressive metastatic renal cell cancer. Urol Oncol 30:290-293

48. Choi YR, Han HS, Lee OJ, Lim SN, Kim MJ, Yeon MH, Jeon HJ et al (2012) Metastatic renal cell carcinoma in a supraclavicular lymph node with no known primary: a case report. Cancer Res Treat 44:215-218

49. Hird AE, Chow E, Ehrlich L, Probyn L, Sinclair E, Yip D, Ko YJ (2008) Rapid improvement in pain and functional level in a patient with metastatic renal cell carcinoma: a case report and review of the literature. J Palliat Med 11:1156-1161

50. Basille D, Andrejak M, Bentayeb H, Kanaan M, Fournier C, Lecuyer E, Boutemy M et al (2010) Bronchial fistula associated with sunitinib in a patient previously treated with radiation therapy. Ann Pharmacother 44:383-386

51. Kelly PJ, Weiss SE, Sher DJ, Perez-Atayde AR, Dal Cin P, Choueiri TK (2010) Sunitinib-induced pseudoprogression after whole-brain radiotherapy for metastatic renal cell carcinoma. J Clin Oncol 28:e433-e435

52. Straka C, Kim DW, Timmerman RD, Pedrosa I, Jacobs C, Brugarolas J (2013) Ablation of a site of progression with stereotactic body radiation therapy extends sunitinib treatment from 14 to 22 months. J Clin Oncol 31:e401-e403

53. Venton G, Ducournau A, Gross E, Lechevallier E, Rochwerger A, Curvale G, Zink JV et al (2012) Complete pathological response after sequential therapy with sunitinib and radiotherapy for metastatic clear cell renal carcinoma. Anticancer Res 32:701-705

54. Escudier B, Roigas J, Gillessen S, Harmenberg U, Srinivas S, Mulder SF, Fountzilas G et al (2009) Phase II study of sunitinib administered in a continuous once-daily dosing regimen in patients with cytokine-refractory metastatic renal cell carcinoma. J Clin Oncol 27:4068-4075

55. George S, Blay JY, Casali PG, le Cesne A, Stephenson P, Deprimo SE, Harmon CS et al (2009) Clinical evaluation of continuous daily dosing of sunitinib malate in patients with advanced gastrointestinal stromal tumour after imatinib failure. Eur $\mathrm{J}$ Cancer 45:1959-1968

56. Corn PG, Song DY, Heath E, Maier J, Meyn R, Kuban D, DePetrillo TA et al (2013) Sunitinib plus androgen deprivation and radiation therapy for patients with localized high-risk prostate cancer: results from a multi-institutional phase 1 study. Int $\mathrm{J}$ Radiat Oncol Biol Phys 86:540-545

57. Chi KH, Liao CS, Chang CC, Ko HL, Tsang YW, Yang KC, Mehta MP (2010) Angiogenic blockade and radiotherapy in hepatocellular carcinoma. Int J Radiat Oncol Biol Phys 78:188-193

58. Wuthrick EJ, Curran WJ Jr, Camphausen K, Lin A, Glass J, Evans J, Andrews DW et al (2014) A pilot study of hypofractionated stereotactic radiation therapy and sunitinib in previously irradiated patients with recurrent high-grade glioma. Int J Radiat Oncol Biol Phys 90:369-375

59. Mehta MP, Rodrigus P, Terhaard CH, Rao A, Suh J, Roa W, Souhami L et al (2003) Survival and neurologic outcomes in a randomized trial of motexafin gadolinium and whole-brain radiation therapy in brain metastases. J Clin Oncol 21:2529-2536 
60. Andrews DW, Scott CB, Sperduto PW, Flanders AE, Gaspar LE, Schell MC, Werner-Wasik M et al (2004) Whole brain radiation therapy with or without stereotactic radiosurgery boost for patients with one to three brain metastases: phase III results of the RTOG 9508 randomised trial. Lancet 363:1665-1672

61. Balana C, Gil MJ, Perez P, Reynes G, Gallego O, Ribalta T, Capellades J et al (2014) Sunitinib administered prior to radiotherapy in patients with non-resectable glioblastoma: results of a phase II study. Target Oncol

62. Neyns B, Sadones J, Chaskis C, Dujardin M, Everaert H, Lv S, Duerinck $\mathbf{J}$ et al (2011) Phase II study of sunitinib malate in patients with recurrent high-grade glioma. J Neurooncol 103:491-501

63. Lewin J, Khamly KK, Young RJ, Mitchell C, Hicks RJ, Toner GC, Ngan SY et al (2014) A phase Ib/II translational study of sunitinib with neoadjuvant radiotherapy in soft-tissue sarcoma. Br J Cancer 111:2254-2261

64. Wuthrick EJ, Kamrava M, Curran WJ Jr, Werner-Wasik M, Camphausen KA, Hyslop T, Axelrod R et al (2011) A phase 1b trial of the combination of the antiangiogenic agent sunitinib and radiation therapy for patients with primary and metastatic central nervous system malignancies. Cancer 117:5548-5559

65. Khuntia D, Brown P, Li J, Mehta MP (2006) Whole-brain radiotherapy in the management of brain metastasis. J Clin Oncol 24:1295-1304

66. Gaspar L, Scott C, Rotman M, Asbell S, Phillips T, Wasserman T, McKenna WG et al (1997) Recursive partitioning analysis (RPA) of prognostic factors in three Radiation Therapy Oncology Group (RTOG) brain metastases trials. Int J Radiat Oncol Biol Phys 37:745-751

67. Kleibeuker EA, Ten Hooven MA, Castricum KC, Honeywell R, Griffioen AW, Verheul HM, Slotman BJ et al (2015) Optimal treatment scheduling of ionizing radiation and sunitinib improves the antitumor activity and allows dose reduction. Cancer Med (in press)

68. Hagiwara M, Hackshaw MD, Oster G (2013) Economic burden of selected adverse events in patients aged $\geq 65$ years with metastatic renal cell carcinoma. J Med Econ 16:1300-1306

69. Czabanka M, Vinci M, Heppner F, Ullrich A, Vajkoczy P (2009) Effects of sunitinib on tumor hemodynamics and delivery of chemotherapy. Int J Cancer 124:1293-1300

70. Nathan P, Zweifel M, Padhani AR, Koh DM, Ng M, Collins DJ, Harris A et al (2012) Phase I trial of combretastatin A4 phosphate (CA4P) in combination with bevacizumab in patients with advanced cancer. Clin Cancer Res 18:3428-3439

71. Yopp AC, Schwartz LH, Kemeny N, Gultekin DH, Gonen M, Bamboat Z, Shia J et al (2011) Antiangiogenic therapy for primary liver cancer: correlation of changes in dynamic contrastenhanced magnetic resonance imaging with tissue hypoxia markers and clinical response. Ann Surg Oncol 18:2192-2199

72. Machiels JP, Henry S, Zanetta S, Kaminsky MC, Michoux N, Rommel D, Schmitz S et al (2010) Phase II study of sunitinib in recurrent or metastatic squamous cell carcinoma of the head and neck: GORTEC 2006-01. J Clin Oncol 28:21-28
73. Hugonnet F, Fournier L, Medioni J, Smadja C, Hindie E, Huchet V, Itti E et al (2011) Metastatic renal cell carcinoma: relationship between initial metastasis hypoxia, change after 1 month's sunitinib, and therapeutic response: an 18F-fluoromisonidazole PET/CT study. J Nucl Med 52:1048-1055

74. Murakami M, Zhao S, Zhao Y, Chowdhury NF, Yu W, Nishijima $\mathrm{K}$, Takiguchi $\mathrm{M}$ et al (2012) Evaluation of changes in the tumor microenvironment after sorafenib therapy by sequential histology and $18 \mathrm{~F}$-fluoromisonidazole hypoxia imaging in renal cell carcinoma. Int J Oncol 41:1593-1600

75. Griffioen AW, Mans LA, de Graaf AM, Nowak-Sliwinska P, de Hoog CL, de Jong TA, Vyth-Dreese FA et al (2012) Rapid angiogenesis onset after discontinuation of sunitinib treatment of renal cell carcinoma patients. Clin Cancer Res 18:3961-3971

76. Kleibeuker EA, Griffioen AW, Verheul HM, Slotman BJ, Thijssen VL (2012) Combining angiogenesis inhibition and radiotherapy: a double-edged sword. Drug Resist Updat 15:173-182

77. Blaszkowsky LS, Ryan DP, Szymonifka J, Borger DR, Zhu AX, Clark JW, Kwak EL et al (2014) Phase I/II study of neoadjuvant bevacizumab, erlotinib and 5-fluorouracil with concurrent external beam radiation therapy in locally advanced rectal cancer. Ann Oncol 25:121-126

78. Kambadakone A, Yoon SS, Kim TM, Karl DL, Duda DG, DeLaney TF, Sahani DV (2015) CT perfusion as an imaging biomarker in monitoring response to neoadjuvant bevacizumab and radiation in soft-tissue sarcomas: comparison with tumor morphology, circulating and tumor biomarkers, and gene expression. AJR Am J Roentgenol 204:W11-W18

79. Sadahiro S, Suzuki T, Tanaka A, Okada K, Saito G, Kamijo A, Akiba T et al (2015) Phase II study of preoperative concurrent chemoradiotherapy with S-1 plus bevacizumab for locally advanced resectable rectal adenocarcinoma. Oncology 88:49-56

80. Chinot OL, Wick W, Mason W, Henriksson R, Saran F, Nishikawa R, Carpentier AF et al (2014) Bevacizumab plus radiotherapy-temozolomide for newly diagnosed glioblastoma. N Engl J Med 370:709-722

81. Meyer JM, Perlewitz KS, Hayden JB, Doung YC, Hung AY, Vetto JT, Pommier RF et al (2013) Phase I trial of preoperative chemoradiation plus sorafenib for high-risk extremity soft tissue sarcomas with dynamic contrast-enhanced MRI correlates. Clin Cancer Res 19:6902-6911

82. Hottinger AF, Aissa AB, Espeli V, Squiban D, Dunkel N, Vargas MI, Hundsberger T et al (2014) Phase I study of sorafenib combined with radiation therapy and temozolomide as first-line treatment of high-grade glioma. Br J Cancer 110:2655-2661

83. Chen SW, Lin LC, Kuo YC, Liang JA, Kuo CC, Chiou JF (2014) Phase 2 study of combined sorafenib and radiation therapy in patients with advanced hepatocellular carcinoma. Int J Radiat Oncol Biol Phys 88:1041-1047

84. Jalali S, Chung C, Foltz W, Burrell K, Singh S, Hill R, Zadeh G (2014) MRI biomarkers identify the differential response of glioblastoma multiforme to anti-angiogenic therapy. Neuro Oncol 16:868-879 